\title{
The successful implementation of the ERAS program among Caesarean deliveries to reduce the postoperative length of hospital stay
}

Tshering Tamang ( $\nabla$ ttamang@mrrh.gov.bt)

Mongar Regional Referral Hospital

Tashi Wangchuk

Mongar Regional Referral Hospital

Choning Zangmo

Mongar Regional Referral Hospital

Tshering Wangmo

Mongar Regional Referral Hospital

Karma Tshomo

Mongar Regional Referral Hospital

Research Article

Keywords: Caesarean deliveries, ERAS, length of hospital stay

Posted Date: April 30th, 2021

DOI: https://doi.org/10.21203/rs.3.rs-442117/v1

License: (a) (i) This work is licensed under a Creative Commons Attribution 4.0 International License.

Read Full License 


\section{Abstract}

Background: Enhanced Recovery After Surgery (ERAS) is a multidisciplinary perioperative care program to optimize and enhance postoperative recovery. It has a beneficial role in decreasing the length of hospital stay and improving the quality of care. This study aims to observe the successful implementation of ERAS in reducing the length of hospital stay (LOS) among Caesarean deliveries.

Methods: A pre-and post-implementation study of ERAS protocol was conducted, among cohort of women who underwent Caesarean deliveries from January to December 2020 in the department of Obstetrics and Gynaecology, Mongar Regional Referral hospital. Data collected retrospectively and analyzed in SPSS (IBM SPSS trial version); and comparison of length of hospital stay between the two groups were tested by t-test.

Results: 171 patients were included in the study: 87 in the pre-ERAS and 84 in the post-ERAS cohort. Post implementation, LOS decreased by an average of 21.0 (CI 16.11-24.64; p-value $<0.001$ ) hours in the postoperative period. A greater proportion of patients were discharged on day-2 (2.3\% in pre-ERAS and $81 \%$ in ERAS; $p$-value $<0.001$ ).

Conclusion: Implementation of ERAS protocol can significantly decrease the postoperative length of hospital stay without increasing the complications and readmission rates.

\section{Background}

Enhanced Recovery After Surgery (ERAS) is a multidisciplinary perioperative care program that combines evidence-based practices to optimize and enhance patient recovery. The goal of the ERAS pathway is to reduce surgical stress and accelerate early physiological and functional recovery in the post-operative period. Its role in decreasing the length of hospital stay, potential complications, readmission rates, and financial burden to the healthcare system have been documented (1-4). The ERAS Society (www.erassociety.org) is an international, multidisciplinary, non-profit organization that has developed guidelines and made recommendations for all surgical disciplines (5). The society recommends to focus on a patient-centric approach and utilize specific elements of ERAS during Caesarean deliveries (CD) in the perioperative period for improved enhancement of the maternal and fetal health outcomes $(6-8)$.

Successful implementation of ERAS protocol among CD require a concerted multidisciplinary team approach and standardization of care to improve quality of patient care $(9,10)$. In many of our hospitals, the utilization of the ERAS pathway in perioperative care has remained a new concept; and has not been implemented in different surgical fields. With the adoption of the ERAS program in our department, we aimed to describe the successful implementation of ERAS protocol with a primary outcome to compare the length of post-operative length hospital stay (LOS) in ERAS and the traditional care among Caesarean deliveries. A secondary aim was to determine surgical complications in the ERAS pathway.

\section{Methods}




\section{Study design, setting, and participants}

After prior protocol approval from Research Ethics Board, Ministry of Health (Ref.No.REBH/Approval/2021/041), we designed a pre- and post-ERAS implementation study retrospectively to include cohort of women who underwent CD in the department of Obstetrics and Gynaecology, Mongar Regional Referral Hospital. The facility department experiences about 800 hundred deliveries annually with Caesarean rate of $34.4 \%$ (11). CD performed in 2020 were reviewed and recruited for this study; irrespective of its indications, type (emergency or elective), co-morbidities (presence or absence), and complications. Exclusion criteria included women who had prolonged stay due to other reasons like preterm delivery, social and financial incapacities, and inability to follow up. Recruited CD from January to June, 2020 was on pre-ERAS care; and those from July to December, 2020 on post-ERAS program. Data variables included patient's basic demographic and obstetric details, Body Mass Index (BMI), associated medical co-morbidities, indication for Caesarean, post-operative LOS in hours, and surgical complications particularly surgical site infection experienced by the patient from immediate postoperative period to 30 days follow up.

\section{Pre-ERAS perioperative care}

Traditionally, the patients scheduled for elective CD were admitted a day prior, and a strict fasting period was ordered from midnight till the time of surgery. Preoperative patient education and counseling, medications and fluid loading were inconsistently practiced. Preoperative oral antibiotics and vaginal cleansing with an antimicrobial solution for emergency $C D$ were not routine. The skin was prepared with povidone-iodine alone. Surgical techniques and skin closure depended upon the experience and expertise of the surgeon. Prevention of hypotension and hypothermia were not routinely ordered by the anesthetist. The liberal intravenous fluid used to be the norm. All patients had prolonged fasting, prolonged immobilization, and longer urinary catheter placement after surgery along with painful intramuscular analgesics. Women were discharged on the third day if clinically stable, and followed-up in the postnatal clinic.

\section{ERAS protocol implementation}

The ERAS protocol was implemented from 1st July 2020 for all gynecological procedures and CD in the department. Before implementation, education of the healthcare personnel from maternity ward, operation theatre, quality division was done focusing on the processes, individual-specific roles; and the standardization of care. Standard Operation Procedure (SoP) was developed and documented by going through the guidelines and the recommendations developed by the ERAS society (2018-19) that were suitable to our setting $(6-8,12)$. The document was distributed to the ward and operation theatre to use it consistently without having to ask the operating surgeons. Besides, a checklist was instituted on the components for each patient to ensure the provision of ERAS care.

\section{ERAS perioperative care}


In the ERAS principle, all parturient women at term pregnancy were provided with information on risks, benefits, and complications of the Caesarean; pain management plan; goals for early feeding, and mobilization were conveyed. Patients were given the option of admission on the day of surgery for a scheduled Caesarean. The practices adopted were from the evidence-based ERAS protocol particularly on the preoperative fasting and medication, intra-operative skin preparation, postoperative early feeding, early mobilization, early catheter removal. These practices were uniformly applied to both emergency and elective CD. Table 1 elaborates the changing practices in the pre- and post-ERAS protocol among CD patients care. Patients who were clinically stable, satisfactorily ambulating, with adequate oral intake and good pain control on oral analgesics were discharged on day 2 of surgery. Any medical condition needing further investigations and care were kept further until stable. Follow-up was done telephonically and personally in the postnatal visits for 30 days. 
Table 1

Perioperative management in pre- and post-ERAS program in Caesarean deliveries practiced in Mongar Regional Referral hospital

Components Pre-ERAS Post-ERAS

Pre-operative

- Fasting Overnight $6 \mathrm{hrs}$ for solid and 2 hrs for clear liquid

- Medication IV Ranitidine; IV Metoclopromide Oral Ranitidine and Antacid;

Acetaminophen $1 \mathrm{gms} 2$ hours prior

- Antibiobiotic IV Cephazolin $2 \mathrm{gm}$ within $1 \mathrm{hr}$

IV Cephazolin $2 \mathrm{gm}$; Oral Azithromycin $1 \mathrm{gm}$ prophylaxis for laboring and membrane ruptured patients

$\begin{array}{lll}\begin{array}{l}\text { - Skin } \\ \text { preparation }\end{array} & \text { Povidone iodine alone } & \begin{array}{l}\text { Alcohol based Chlorohexidine or lodine- } \\ \text { Alcohol mixed-preparation }\end{array} \\ \begin{array}{l}\text {-Vaginal } \\ \text { preparation }\end{array} & \text { None } & \text { Povidone iodine for all emergency cases }\end{array}$

Intraoperative

-Anaesthesia Neuraxial Neuraxial

- Analgesia None LA infiltration of wound

Inj. PCM 600mg IM

- Hypothermia None prevention

Forced air/ Temperature monitoring

- Surgical procedure

Blunt technique

Skin - Interrupted suture

\section{Blunt technique}

Re-approximation of subcutaneous layer if thickness $>2 \mathrm{~cm}$

Skin - Subcutaneous suture

- Fluid

management

- New born care

Delayed cord cutting and early essential neonatal care not part of routine care
Routinely done

\section{Goal directed, Early stopping of IV fluids}

Liberal $\sim 4$ to 5 litres till next day

\section{Postoperative}

- Analgesia

IM Pethidine and IM Diclofenac

- Feeding and parental fluid restricting 


\begin{tabular}{|lll|}
\hline Components & Pre-ERAS & Post-ERAS \\
\hline - Mobilization & Not done until next day & $\begin{array}{l}\text { Routinely done after six hrs } \\
\text { Physiotherapy from day } 1\end{array}$ \\
\hline $\begin{array}{l}\text { - Catheter } \\
\text { removal }\end{array}$ & Kept till next day & Routinely removed after six hrs \\
\hline
\end{tabular}

\section{Study outcomes}

The primary outcome for our study was the postoperative length of hospital stay (LOS) from the time of surgery till discharge calculated in numbers of hours for all cases of CD before or after the implementation of ERAS. We also looked at the surgical complication rates following surgery particularly surgical site infection and readmission due to any cause.

\section{Statistical analysis}

The data management and validation was done using Epidata (version 3.1) and statistical analysis was done using SPSS (IBM SPSS Trial version). Obstetrics variables were analyzed using descriptive tests like proportion and percentages. Continuous variables were compared between the two groups by t-test and categorical variables by chi-square test. $p$-value $<0.05$ and $95 \% \mathrm{Cl}$ was used to calculate the level of significance.

\section{Results}

A total of 176 women underwent CD during the year 2020, 91 in pre-ERAS and 85 in post ERAS arm. Four women in pre-ERAS and one in the post-ERAS group were excluded after confirming their prolonged stay due to preterm delivery, financial and social reasons. 87 women before and 84 after ERAS introduction were eligible for analysis. In both the groups, homogeneous distribution was observed in demographic, preoperative characteristics, CD, and its indications. The mean age in the pre-ERAS (29.2 \pm 6.1 years) and post-ERAS ( $29.6 \pm 6$.3years) group were not statistically significant. The mean parity was also not significant statistically. The proportion of co-morbid conditions like hypertensive disorders $(10.3 \% \mathrm{vs}$ $14.3 \%)$, GDM (2.3\% vs $2.4 \%)$, anemia ( $5.7 \%$ vs $9.5 \%$ ) and obesity ( $17.2 \%$ vs $19.0 \%)$ were slightly higher in post-ERAS care. More elective CDs were done in both the groups (55.2\% and $56.0 \%)$. Previous Caesarean was the commonest indication for $\mathrm{CD}(42.5 \%$ and $44.0 \%)$. The difference in postoperative-hemoglobin level between the two groups was not significant (p-value0.22); only small numbers received blood transfusion (3.4\% and $4.7 \%$ ). Table 2 describes the demographic and clinical characteristics of women who underwent CD in 2020. 
Table 2

Demographic and clinical characteristics of women who underwent CD in 2020 in Mongar Regional Referral hospital

\begin{tabular}{|c|c|c|c|}
\hline Demography & Pre-ERAS $(n=87)$ & Post-ERAS care $(n=84)$ & $\begin{array}{l}\text { Significance } \\
\text { "p" value }\end{array}$ \\
\hline Mean Age & $29.3 \pm 6.1$ & $29.7 \pm 6.3$ & 0.68 \\
\hline \multicolumn{4}{|l|}{ Parity } \\
\hline $0-1$ & $58(66.7 \%)$ & $51(60.7 \%)$ & \multirow[t]{2}{*}{0.51} \\
\hline$\geq 2$ & $29(33.3 \%)$ & $33(39.3 \%)$ & \\
\hline \multicolumn{4}{|l|}{ Co-morbidities } \\
\hline Hypertension & $9(10.3 \%)$ & $12(14.3 \%)$ & 0.76 \\
\hline GDM & $2(2.3 \%)$ & $2(2.4 \%)$ & 1.0 \\
\hline Anemia & $5(5.7 \%)$ & $9(10.7 \%)$ & 0.56 \\
\hline Obesity & $15(17.2 \%)$ & $13(15.5 \%)$ & 0.27 \\
\hline \multicolumn{4}{|l|}{ Caesarean } \\
\hline Emergency & $39(44.8 \%)$ & $37(44.0 \%)$ & \\
\hline Elective & $48(55.2 \%)$ & $47(56.0 \%)$ & \\
\hline \multicolumn{4}{|l|}{ Indications } \\
\hline Past CS & $37(42.5 \%)$ & $37(44.0 \%)$ & 0.84 \\
\hline Fetal indications & $28(32.2 \%)$ & $23(27.4 \%)$ & 0.49 \\
\hline Maternal indications & $7(8.0 \%)$ & $9(10.7 \%)$ & 0.54 \\
\hline Labour dystocia & $6(6.9 \%)$ & $9(10.7 \%)$ & 0.38 \\
\hline Others & $9(10.3 \%)$ & $6(7.1 \%)$ & 0.46 \\
\hline Pre-op hemoglobin & $12.6 \pm 1.1$ & $11.9 \pm 1.3$ & 0.00 \\
\hline Post-op hemoglobin & $10.5 \pm 1.2$ & $10.3 \pm 1.3$ & 0.33 \\
\hline Blood transfusion & $2(2.3 \%)$ & $4(4.8 \%)$ & 0.44 \\
\hline
\end{tabular}

After ERAS implementation, the postoperative length of stay was significantly lower than in pre-ERAS care. The mean time was reduced by 21.0 hours $(\mathrm{Cl} 16.11-24.64$; $\mathrm{p}$-value $<0.001)$ in the postoperative period. A higher proportion of patients were discharged on day 2 in post-ERAS arm (82.1\%) compared to pre-ERAS (3.2\%) arm ( $p$-value < 0.001$)$. The differences were also observed in emergency and elective CD. In the pre- and post ERAS implementation the mean LOS in emergency and elective reduced by 23 and 
19.3 hours respectively, which were independently significant. A greater proportion of patients were discharged on day-2 $(2.3 \%$ in pre-ERAS and $81 \%$ in ERAS; $p$-value $<0.001)$

Thirty days follow-up after surgery revealed, surgical site infection was the main complication for readmission in both groups. Three (3.4\%) women in pre-ERAS arm and two $(2.4 \%)$ in post-ERAS arm required debridement and re-suturing in the operation theatre. The anaesthetic complications included nausea and vomiting, spinal headache. Table 3 depicts the LOS and complications experienced by the women in two groups.

Table 3

Postoperative length of stay and complications experienced by in the pre-and-post ERAS groups

\begin{tabular}{|llll|}
\hline & $\begin{array}{l}\text { PreERAS( } \mathbf{n}= \\
\mathbf{8 7})\end{array}$ & $\begin{array}{l}\text { Post ERAS( } \mathbf{n}= \\
\mathbf{8 4})\end{array}$ & $\begin{array}{l}\text { Significance(p } \\
\text { value) }\end{array}$ \\
\hline $\begin{array}{l}\text { Postoperative length of stay } \\
\text { (hours) }\end{array}$ & & & \\
\hline Overall & $72.7 \pm 13.4$ & $51.7 \pm 15.4$ & 0.00 \\
\hline Range & $48-175$ & $24-116$ & \\
\hline - Emergency CD & $74.3 \pm 19.3$ & $51.3 \pm 17.2$ & 0.00 \\
\hline - Elective CD & $71.4 \pm 5.0$ & $52.1 \pm 14.0$ & 0.00 \\
\hline Discharges & & & 0.00 \\
\hline Day 2 & $2(2.3 \%)$ & $68(81.0 \%)$ & \\
\hline Complications & & $2(2.4 \%)$ & 0.63 \\
\hline SSI & $3(3.4 \%)$ & $3(3.6 \%)$ & 1.0 \\
\hline Readmission & $3(3.4 \%)$ & $2(2.4 \%)$ & 0.63 \\
\hline Postop nausea \& vomiting & $2(2.3 \%)$ & $9(10.7 \%)$ & 0.66 \\
\hline Post spinal headache & $10(11.5 \%)$ & $1(1.2 \%)$ & 1.0 \\
\hline UTI & $1(1.1 \%)$ & & \\
\hline
\end{tabular}

\section{Discussions}

The main intent of implementing the ERAS program was to promote patients' early return to mobility and function, to reduce the length of stay in the hospital, and to decrease rates of post-surgical complications. Our study demonstrated a statistically significant reduced postoperative length of stay by 21.0 hours after ERAS implementation compared to the traditional care without increasing the complication and readmission rates. The findings of shorter length were consistent with the study done by Mullman et al, who was able to demonstrate a reduction of LOS by 0.8 days (13). Due to shorter stay, a decrease in the hospital associated costs has been observed along with the reduction in administration of opioids in the 
postoperative period $(2,14)$.This implicates a reduction in expenditure for free healthcare like ours in Bhutan where the sole funding comes from the state.

Most of the studies on ERAS have been done in high-income countries and among elective CD where planning and application of all elements of ERAS were possible. Among emergency CD, all components of pre-operative care are not applicable, unlike a planned CD. The difference in LOS and complication rates in both elective and emergency CD was not significant as observed in our data. The LOS in our emergency $C D$ was similar to the randomized controlled trial conducted in one of the African referral hospitals which demonstrated a reduction by 18.5 hours in LOS in emergency CD after ERAS implementation(15). Early oral intake, early ambulation, and early catheter removal in the postoperative period might have played important role in faster recovery.

An early discharge from the hospital is one of the hallmarks of ERAS pathway adoption. In our study, day 2 hospital discharges after the implementation was significantly and proportionately higher ( $81 \% \mathrm{vs}$ $2.3 \%$ ); which was as opposed to the pre-ERAS where greater day 3 discharges were observed (88.8\%). A study by Wrench et.al in their tertiary center also concluded that a greater proportion of patients discharged on Day 1 can be achieved after the ERAS program without compromising the quality(16).

Before the introduction of the ERAS protocol, the practice of perioperative care in our department was not standardized and heavily dependent on the operating surgeon. The success of our protocol was driven by the multidisciplinary approach of the ERAS program which provided a standard procedure of peripartum care for all parturient mothers. It is noteworthy to explain that, compliance to the protocol guidelines was strictly adhered by the operating surgeon, nursing staffs, and anesthesia team. Much of the success is attributed to the collaborative care imparted by the nursing team. Although it appears to increase the workload of nursing staff to adhere to many elements of ERAS care, the overall load is substantially lower due to shorter hospital stay(17).

There is growing evidence that ERAS protocol in CD is safe, feasible, and effective. The newer shreds of evidence and practices have been published by ERAS society in three parts (6-8). Recent consensus and recommendation had been made by Society for Obstetric Anesthesia and Perinatology (18). Our protocol development was in uniformity with these guidelines. Some of the positive changes observed in our ward were; avoiding prolonged fasting, limiting parental fluid and encouraging oral intake as early as in 3 hours post operatively, assisting to mobilize after 6 hours, removing urinary catheter at 6 hours, practicing early essential newborn care (skin to skin contact); and discharging the mother home early. Implementing the ERAS protocol is not difficult and it is associated with several improved maternal and fetal outcomes which are well documented and conveyed by earlier studies $(13,19)$.

This study is not without limitation. It only reveals the postoperative length of stay of the mother. It does not dwell on the total duration of stay in the hospital, because some mothers tend to stay pre-operatively due to financial reasons and distance from the hospital. The discharge criteria were formulated for the mothers only. Some babies are admitted for the continuation of care which prolongs their stay. The study does not describe this in the exclusion criterion. It was also difficult to demonstrate which individual 
element of ERAS had the profound effect. However, this study has portrayed the success of the implementation of the ERAS pathway which forms a basis for future implementation in other hospitals and surgical specialties.

\section{Conclusion}

Implementation of ERAS protocol can significantly decrease the postoperative length of hospital stay without increasing the complications and readmission rates. Such quality improvement initiatives and evidence-based practices need to be adopted in our surgical practices to improve the peripartum care of the mothers and the babies. It is additionally more significant due to its success in a young nation like Bhutan.

\section{Declarations}

\section{Ethics approval and consent to participate}

- We confirm that, this research project has abided the rules and regulation of Research Ethics Board of Bhutan, Ministry of Health. This retrospective study has been performed inaccordance with the Declaration of Helsinki. Protocol approval (Ref.No.REBH/Approval/2021/041) has been obtained prior conduct of this study. Waiver of informed consent from the participants has been approved from the Board. Protocol approval letter is submitted for kind reference.

\section{Consent for publication}

- Not application

\section{Availability of data and materials}

- Data set is available and will be shared in supplementary files Excel format

\section{Competing interests}

- The authors declare there is no competing interest financially or non-financially

\section{Funding}

- Reproductive health program, Ministry of Health; Bhutan has funded for data collection and analysis process

\section{Authors' contributions}

- TT: Principal Investigator and corresponding author, concept, design of the protocol, data collection, data analysis / interpretation, drafting / critically reviewing the paper, giving approval for the final version to be published 
- TW: concept / design of the protocol, data analysis / interpretation, critically reviewing the paper, giving approval for the final version to be published

- CZ, TW, KT: data collection, interpretation, critically reviewing the paper, giving approval for the final version to be published

\section{Acknowledgement:}

- We would like to acknowledge the hospital administration, nursing and technical staffs who supported the implementation of ERAS program.

\section{Authors' information}

- Tshering Tamang, Obstetrician and Gynaecologist, Department of Obstetrics and Gynaecology, Mongar Regional Referral Hospital, Bhutan. Mobile: +0975-17797926, Email: ttamang@mrrh.gov.bt

\section{References}

1. Teigen NC, Sahasrabudhe N, Doulaveris G, Xie X, Negassa A, Bernstein J, et al. Enhanced recovery after surgery at cesarean delivery to reduce postoperative length of stay: a randomized controlled trial. Am J Obstet Gynecol [Internet]. 2020 Apr;222(4):372.e1-372.e10. Available from: https://doi.org/10.1016/j.ajog.2019.10.009

2. Fay EE, Hitti JE, Delgado CM, Savitsky LM, Mha EBM, Slater JL, et al. An enhanced recovery after surgery pathway for cesarean delivery decreases hospital stay and cost. Am J Obstet Gynecol [Internet]. 2019;1.e1-9. Available from: https://doi.org/10.1016/j.ajog.2019.06.041

3. Scheib SA, Thomassee M, Kenner JL. Enhanced Recovery after Surgery in Gynecology: A Review of the Literature. J Minim Invasive Gynecol [Internet]. 2019 Feb;26(2):327-43. Available from: https://doi.org/10.1016/j.jmig.2018.12.010

4. Pache B, Joliat G, Hübner M, Grass F, Demartines N, Mathevet P, et al. Cost-analysis of Enhanced Recovery After Surgery (ERAS) program in gynecologic surgery. Gynecol Oncol [Internet]. 2019 Aug;154(2):388-93. Available from: https://doi.org/10.1016/j.ygyno.2019.06.004

5. Altman AD, Helpman L, McGee J, Samouëlian V, Auclair M-H, Brar H, et al. Enhanced recovery after surgery: implementing a new standard of surgical care. Can Med Assoc J [Internet]. 2019 Apr 29;191(17):E469-75. Available from: http://www.cmaj.ca/lookup/doi/10.1503/cmaj.180635

6. Wilson RD, Caughey AB, Wood SL, Macones GA, Wrench IJ, Huang J, et al. Guidelines for Antenatal and Preoperative care in Cesarean Delivery: Enhanced Recovery After Surgery Society

Recommendations (Part 1). Am J Obstet Gynecol [Internet]. 2018 Dec;219(6):523.e1-523.e15. Available from: https://doi.org/10.1016/j.ajog.2018.09.015

7. Caughey AB, Wood SL, Macones GA, Wrench IJ, Huang J, Norman M, et al. Guidelines for intraoperative care in cesarean delivery: Enhanced Recovery After Surgery Society Recommendations 
(Part 2). Am J Obstet Gynecol [Internet]. 2018 Dec;219(6):533-44. Available from: https://doi.org/10.1016/j.ajog.2018.08.006

8. Macones GA, Caughey AB, Wood SL, Wrench IJ, Huang J, Norman M, et al. Guidelines for postoperative care in cesarean delivery: Enhanced Recovery After Surgery (ERAS) Society recommendations (part 3). Am J Obstet Gynecol [Internet]. 2019 Sep;221(3):247.e1-247.e9. Available from: https://doi.org/10.1016/j.ajog.2019.04.012

9. Kleiman AM, Chisholm CA, Dixon AJ, Sariosek BM, Thiele RH, Hedrick TL, et al. Evaluation of the impact of enhanced recovery after surgery protocol implementation on maternal outcomes following elective cesarean delivery. Int J Obstet Anesth [Internet]. 2020 Aug;43:39-46. Available from: https://doi.org/10.1016/j.ijoa.2019.08.004

10. Suharwardy S, Carvalho B. Enhanced recovery after surgery for cesarean delivery. Curr Opin Obstet Gynecol [Internet]. 2020 Apr;32(2):113-20. Available from: http://journals.Iww.com/10.1097/GC0.0000000000000616

11. Tamang T, Dema J, Pelden S, Choden P. Usefulness of Robson classification system to analyze caesarean section deliveries: a hospital based study. Bhutan Heal J [Internet]. 2020 May 15;6(1):3844. Available from: http://bhj.com.bt/index.php/bhj/article/view/100

12. Nelson G, Bakkum-Gamez J, Kalogera E, Glaser G, Altman A, Meyer LA, et al. Guidelines for perioperative care in gynecologic/oncology: Enhanced Recovery After Surgery (ERAS) Society recommendations-2019 update. Int J Gynecol Cancer [Internet]. 2019 May;29(4):651-68. Available from: http://ijgc.bmj.com/lookup/doi/10.1136/ijgc-2019-000356

13. Mullman L, Hilden P, Goral J, Gwacham N, Tauro C, Spinola K, et al. Improved Outcomes With an Enhanced Recovery Approach to Cesarean Delivery. Obstet Gynecol [Internet]. 2020 Oct;136(4):68591. Available from: https://journals.Iww.com/10.1097/AOG.0000000000004023

14. Shinnick JK, Ruhotina M, Has P, Kelly BJ, Brousseau EC, O'Brien J, et al. Enhanced Recovery after Surgery for Cesarean Delivery Decreases Length of Hospital Stay and Opioid Consumption: A Quality Improvement Initiative. Am J Perinatol [Internet]. 2020 Jun 2;1(212). Available from:

http://www.thieme-connect.de/DOI/DOI?10.1055/s-0040-1709456

15. Baluku M, Bajunirwe F, Ngonzi J, Kiwanuka J, Ttendo S. A Randomized Controlled Trial of Enhanced Recovery After Surgery Versus Standard of Care Recovery for Emergency Cesarean Deliveries at Mbarara Hospital, Uganda. Anesth Analg [Internet]. 2020 Mar;130(3):769-76. Available from: http://journals.Iww.com/10.1213/ANE.0000000000004495

16. Wrench IJ, Allison A, Galimberti A, Radley S, Wilson MJ. Introduction of enhanced recovery for elective caesarean section enabling next day discharge: a tertiary centre experience. Int J Obstet Anesth [Internet]. 2015 May;24(2):124-30. Available from:

http://dx.doi.org/10.1016/j.ijoa.2015.01.003

17. Liu Z, Du W, Yao S. Enhanced recovery after cesarean delivery: a challenge for anesthesiologists. Chin Med J (Engl) [Internet]. 2020 Mar 5;133(5):590-6. Available from: http://journals.Iww.com/10.1097/CM9.0000000000000644 
18. Bollag L, Lim G, Sultan P, Habib AS, Landau R, Zakowski M, et al. Society for Obstetric Anesthesia and Perinatology: Consensus Statement and Recommendations for Enhanced Recovery After Cesarean. Anesth Analg [Internet]. 2020 Nov 3;Publish Ah(Xxx):1-16. Available from: https://journals.Iww.com/10.1213/ANE.0000000000005257

19. Huang J, Cao C, Nelson G, Wilson RD. A Review of Enhanced Recovery After Surgery Principles Used for Scheduled Caesarean Delivery. J Obstet Gynaecol Canada [Internet]. 2019 Dec;41(12):1775-88. Available from: https://doi.org/10.1016/j.jogc.2018.05.043

\section{Supplementary Files}

This is a list of supplementary files associated with this preprint. Click to download.

- AERASFINAL.xIsx 